(6) Die Regierungsbildung lief im Grunde schon am Wahlabend auf die Dänen-Ampel zu; nur CDU-Spitzenkandidat de Jager verwehrte sich dieser Einsicht noch einige Tage. Die Bildung dieser in Deutschland neuartigen Koalition ging mit 38 Tagen zügig vonstatten. Im Koalitionsvertrag können sich alle Parteien mit ihren inhaltlichen Positionen wiederfinden; die Ressortverteilung ist gemessen an der Stärkerelation der Koalitionspartner sehr gerecht. Die Grünen, die mathematisch ein klein wenig zu kurz kamen, wurden mit zwei Schlüsselministerien (Energiewende, Finanzen) entschädigt.

(7) Den drei Regierungsparteien stehen mit CDU, FDP und den Piraten auch drei Oppositionsparteien gegenüber. Die Piraten wollen allerdings sachorientiert entscheiden und stehen deshalb einer Zusammenarbeit mit der Regierung offen gegenüber. Die innenpolitischen Beschlüsse der Koalition (Senkung des Wahlalters auf 16 Jahre, Ablehnung der Vorratsdatenspeicherung) ermöglichten es wahrscheinlich zwei Piraten, bei der Wahl des Ministerpräsidenten für Albig zu stimmen.

\title{
Die nordrhein-westfälische Landtagswahl vom 13. Mai 2012: Von der Minderheit zur Mehrheit
}

\author{
Stefan Bajohr
}

Die Wahl zum Landtag am 13. Mai 2012 kam nicht unerwartet, aber überraschend. Seit der Bildung einer rot-grünen Minderheitsregierung im November 2010 hatten Medien und Politik spekuliert, wie lange sich diese Koalition halten könne. Manche meinten, dass sie bereits daran scheitern würde, einen Haushalt durch das Parlament zu bringen. Sie sahen sich getäuscht. Die relative Stabilität der Landesregierung beruhte darauf, dass die Opposition ihre Mehrheit nicht in einem konstruktiven Misstrauensvotum gegen die Ministerpräsidentin bündeln konnte und mit Blick auf ihre Umfragewerte kein Interesse hatte, Neuwahlen herbeizuführen.

Als es schließlich doch zur Landtagsauflösung kam, waren ausgerechnet die Parteipolitiker* am meisten verblüfft. Einige von ihnen hatten gezündelt, aber den Brand nicht vorausgesehen.

\section{Die Ausgangslage}

Nach der für Schwarz-Gelb verloren gegangenen Landtagswahl vom 9. Mai 2010 wagte die Sozialdemokratin Hannelore Kraft nach anfänglichem Zögern das Experiment einer rotgrünen Minderheitsregierung. Mit 90 Stimmen von SPD und Grünen bei Enthaltung der Linken (elf Stimmen) und 80 Gegenstimmen von CDU und FDP wurde sie zur Minister-

* Dieser Aufsatz wurde ursprünglich in geschlechtsneutraler Sprache verfasst. Die ZParl-Redaktion samt ihrer Chefredakteurin teilt die Auffassung des Autors, dass Sprache Wirklichkeit gestaltet. Sie meint aber, dass die geschlechtsneutrale Fassung schwerer lesbar sei und bevorzugt deshalb die traditionelle Schreibweise. 
präsidentin gewählt. Kraft setzte auf Gespräche und Verhandlungen mit der Opposition und brachte in 20 Monaten mit wechselnden Mehrheiten wegweisende Entscheidungen zustande: (a) mit der Linken die Abschaffung der Studienbeiträge (24. Februar 2011), die Gebührenfreiheit für das dritte Kindergartenjahr (22. Juli 2011) und die Wiedereinführung der Tariftreueregelung (21. Dezember 2011); (b) mit der CDU einen Schulkonsens, der eine Sekundarschule für die Klassen 5 bis 10 mit gymnasialen Standards schuf (19. Juli 2011); (c) mit der FDP den „Stärkungspakt Stadtfinanzen“ (8. Dezember 2011); (d) mit CDU und FDP den Beschluss zur Schaffung kommunaler Integrationszentren (8. Februar 2012).

Solche Teilerfolge kompensierten indes nicht die haushaltspolitischen Verwerfungen. Zwar konnten sowohl der Nachtragsetat 2010 als auch der Haushalt 2011 verabschiedet werden, da sich die Linke ihrer Stimmen enthielt. Die CDU reichte gegen beide Haushalte Klage ein, weil die Kreditermächtigungen die Verfassungsgrenze durchbrachen. Am 18. Januar 2011 stoppte der Verfassungsgerichtshof in Münster den Nachtragshaushalt und erklärte ihn am 15. März 2011 für verfassungswidrig.

Der Haushaltsentwurf 2012 unterschritt den zulässigen Kreditrahmen um 190 Millionen Euro. Wie in den Vorjahren baute Rot-Grün darauf, bis zur dritten Lesung Zeit zu haben und den Haushaltsentwurf dann durch eine Stimmenthaltung der Linken und/oder der FDP durch den Landtag bringen zu können. In dieser Hoffnung bestärkte sie die Nachsicht der FDP gegenüber den als „Tatkraft“-Touren bezeichneten Betriebsbesichtigungen, die die Ministerpräsidentin aus Landesmitteln finanzieren ließ. CDU und Linke kritisierten dies, weil die Touren in gleicher Form bereits vor 2010 als SPD-Veranstaltungen stattgefunden hatten. Im Raume stand der Vorwurf einer verdeckten Parteienfinanzierung.

Die Rücksichtnahme der FDP endete kurz vor der zweiten Lesung des Haushaltsgesetzes. Nun erklärte der Vorsitzende der Landtagsfraktion, dass man zwar keine Neuwahlen anstrebe, aber „alle Einzelpläne der Regierung ablehnen“ werde, sofern nicht „nennenswerte Einsparungen" vorgenommen würden. ${ }^{1}$ Auch die Linke kündigte ihr Nein an. Beide Ansagen wurden jedoch weniger als kategorische Neins denn als Verhandlungsangebote verstanden. Man ging davon aus, dass weder die FDP noch die Linke die Auflösung des Landtags riskieren würden.

Trotzdem ließ Landtagsdirektor Peter Jeromin die Rechtsfolgen eines Neins prüfen. Die Landtagsverwaltung kam zu dem Schluss, dass „die Ablehnung eines Einzelplans in der 2. Lesung zum Scheitern des Haushalts führen“ könne, „die in der 3. Lesung [...] nicht mehr korrigiert werden kann “2 . Auf diesem Hintergrund erklärte die Ministerpräsidentin den Haushalt 2012 zur unverzichtbaren Geschäftsgrundlage ihrer Regierungstätigkeit. Sollte ein Einzelplan in der zweiten Lesung keine Mehrheit finden, werde sie die „Koalitionsfraktionen bitten, einen Antrag auf Selbstauflösung des Landtages zu stellen, um damit Neuwahlen einzuleiten"3.

Es war dies der Zeitpunkt, an dem der CDU-Landesvorsitzende Norbert Röttgen kundtat, seine Partei in den Wahlkampf führen und die CDU wiederum zur stärksten Fraktion machen zu wollen. Dies war insofern ambitioniert, als YouGov zeitgleich meldete, dass Hannelore Kraft bei einer Direktwahl mit 42 Prozent vor Röttgen rangierte, der gerade einmal 21 Pro-

1 Vgl. Interview mit Gerhard Papke, in: Rheinische Post online vom 12. März 2012, http://www. rp-online.de/politik/nrw/keine-partei-will-neuwahlen-1.2750165 (Abruf am 10. Mai 2012).

2 Landtagsverwaltung NRW, Vermerk vom 13. März 2012, S. 1.

3 Landtag Nordrhein-Westfalen, Plenarprotokoll 15/57 vom 14. März 2012, S. 5713. 
zent erreichen würde. ${ }^{4}$ Infratest dimap sah die SPD mit 38 Prozent deutlich vor der CDU (34 Prozent). Die Grünen, denen Forsa im Oktober 2010 beachtliche 19 Prozent zugeschrieben hatte, mussten ihre Erwartungen zurückschrauben. Im März 2012 lagen sie für Infratest dimap nur noch bei 14 Prozent. Der FDP und der Linken wurde ein Ausscheiden aus dem Landtag vorhergesagt. ${ }^{5}$ Bei rationaler Abwägung konnten also allein SPD und Grüne Interesse an Neuwahlen haben. Dennoch legten sich bis zum Morgen des 14. März 2012 alle Fraktionen auf die Selbstaufösung fest. Nachdem der erste aufgerufene Einzelplan keine Mehrheit gefunden hatte, löste sich der Landtag ohne Enthaltungen einstimmig auf.

\subsection{Bundespolitische Faktoren}

Während CDU-Generalsekretär Hermann Gröhe frohlockte, dass „Krafts rot-grünes Minderheitsexperiment [...] heute grandios gescheitert "6 sei, interpretierte FDP-Generalsekretär Patrick Döring die Landtagsauflösung als „Ausweis unserer funktionierenden demokratischen Kultur"7. Die Ministerpräsidentin kündigte an, nicht noch einmal eine Minderheitsregierung bilden zu wollen, weil eine solche Konstellation auf der Bundesebene nicht kraftvoll genug agieren könne. ${ }^{8}$

Die Bundeskanzlerin wollte vor allem nicht in die absehbare Niederlage der nordrheinwestfälischen CDU hineingezogen werden. Sie betonte, dass die Bundesregierung von der Landtagswahl „unberührt“ bleibe. ${ }^{9}$ Demgegenüber erinnerten SPD und Grüne daran, dass sich frühere Wahlen in Nordrhein-Westfalen durchaus auf den Bund ausgewirkt hätten. So habe die Bildung einer sozialliberalen Koalition in Düsseldorf 1966 die Regierung Brandt/ Scheel 1969 vorweggenommen. 1995 sei Rot-Grün in Düsseldorf der Vorläufer für Rot-Grün 1998 in Bonn gewesen und die rot-grüne Wahlniederlage 2005 in NRW habe die Kanzlerschaft Gerhard Schröders vorzeitig beendet. Warum also sollte eine Stabilisierung von RotGrün in Düsseldorf nicht ein Vorzeichen für den Ausgang der Bundestagswahl 2013 sein?

Landtagsauflösung und Landtagswahl fanden auf dem Hintergrund großer Unzufriedenheit mit der Politik der Bundesregierung statt. Die Zustimmung zur christlich-liberalen Koalition in Berlin war bald nach der letzten Bundestagswahl wegen zahlreicher Pannen und Unstimmigkeiten fortlaufend gesunken. Dem entsprach, dass Schwarz-Gelb seit Konstituierung der Bundesregierung keine Landtagswahl mehr gewonnen hatte. Anfang Mai lagen CDU/CSU und FDP bei der Sonntagsfrage auf Bundesebene bei 38 Prozent. ${ }^{10}$

Für die FDP stand viel auf dem Spiel. Das Wort „Schicksalswahl“, das der Bundesvorsitzende Philipp Rösler und der Spitzenkandidat Christian Lindner bemühten, war keineswegs

4 Vgl. Umfrage: Rot-Grün in NRW kann auf Mehrheit hoffen - FDP raus, in: dapd vom 14. März 2012 .

5 Vgl. www.wahlrecht.de/umfragen/landtage/nrw.htm (Abruf am 17. Juni 2012).

6 Spiegel online vom 14. März 2012, http://www.spiegel.de/politik/deutschland/reaktionen-auf-dieneuwahlen-in-nordrhein-westfalen-a-821388.html (Abruf am 11. Mai 2012).

7 Vgl. Welt online vom 15. März 2012, http://www.welt.de/politik/deutschland/article13922751/ FDP-ist-gut-aufgestellt-fuer-den-Spontanwahlkampf.html (Abruf am 10. Mai 2012).

8 Vgl. Welt online vom 3. Mai 2012, http://www.welt.de/politik/wahl/nrw-wahl/article106253510/ Lindner-nutzt-TV-Runde-zum-Flirt-mit-Rot-Gruen.html (Abruf am 10. Mai 2012).

9 Vgl. Zeit online vom 14. März 2012, http://www.zeit.de/politik/deutschland/2012-03/nrw-haushalt-koalition/komplettansicht (Abruf am 15. Mai 2012).

10 Vgl. http://www.wahlrecht.de/umfragen/index.htm (Abruf am 17. Juni 2012). 
überzogen. Selbstverständlich hing von der Landtagswahl nicht das Schicksal der Menschen in Nordrhein-Westfalen ab. Schon eher ging es - wenngleich sich Döring beeilte, dieser Ansicht zu widersprechen ${ }^{11}$-, um das Schicksal der schwarz-gelben Bundesregierung. Im Kern aber schrieb das Wort die Gefahr des endgültigen Untergangs der FDP als Organisation des politischen Liberalismus in Deutschland an die Wand. Es gehe, so Rösler, „um die Zukunft der Liberalen in Deutschland"12. Er übersah, dass der Liberalismus längst dabei war, sich von der programmatisch ausgezehrten ${ }^{13} \mathrm{FDP}$ zu trennen und in den Grünen und (möglicherweise) der Piratenpartei eine neue Heimat zu finden.

Für die CDU wirkte sich nachteilig aus, dass die ihr ansonsten nahestehende Großindustrie den Spitzenkandidaten fallen ließ; Röttgen galt der Industrie als „zu grün“. ${ }^{14}$ Als er dann noch die Landtagswahl auch als Abstimmung über die Währungspolitik zu deuten und die Bundeskanzlerin in den befürchteten Abwärtsstrudel hineinzuziehen versuchte (,Angela Merkel kann nicht glaubwürdig und stark nach außen auftreten, wenn im größten Bundesland auch Verschuldung offensiv betrieben wird.“), blies ihm scharfer Wind aus Berlin entgegen. Gröhe bestätigte zwar, dass es um eine „Richtungswahl“ gehe; sie habe aber nichts mit dem Kurs der Kanzlerin zu tun. ${ }^{15}$ Der Kanzlerin war die Wahl wichtig für NordrheinWestfalen, aber „nicht mehr und nicht weniger"16. So musste sich Röttgen korrigieren: „Nicht der Kurs von Angela Merkel in Europa“ stehe „zur Abstimmung, sondern der Schuldenkurs von Frau Kraft in Nordrhein-Westfalen"17. Am Freitag vor der Landtagswahl demütigten dann ausgerechnet christdemokratische Ministerpräsidenten den Kandidaten der CDU. Gemeinsam mit rot-grün regierten Ländern überwiesen sie seinen Gesetzentwurf zur Kürzung von Subventionen für Solarstrom an den Vermittlungsausschuss.

Bundesweit hohe Wellen schlugen Anfang Mai Gewaltausbrüche von Salafisten. In Köln ließen sich die Religiösen von Spießgesellen der neofaschistischen ProNRW provozieren, die in diesem Landtagswahlkampf vor Moscheen aufmarschierten und mit der Parole „Freiheit statt Islam“ die Zustimmung ausländerfeindlicher Bevölkerungskreise gewinnen wollten. Weil die Salafisten Waffengewalt einsetzten, versprach die Ministerpräsidentin, den Druck auf sie „maximal zu erhöhen“18.

Beachtung fand auch die Einmischung von SPD-Oberbürgermeistern aus dem Ruhrgebiet in den laufenden Wahlkampf. Ihrer Konsolidierungspolitik müde, erklärten sie die Finanzhilfen für Ostdeutschland zu Ursachen für ihre großenteils hausgemachten Probleme

11 Vgl. SZ online vom 16. März 2012, http://www.sueddeutsche.de/politik/liberale-in-der-krise-fdpchef-roesler-erklaert-nrw-zur-schicksalswahl-1.1310541 (Abruf am 11. Mai 2012); Spiegel online vom 18. März 2012, http://www.spiegel.de/politik/deutschland/roettgen-verweigert-merkel-bekenntnis-zu-nrw-a-822039.html (Abruf am 11. Mai 2012).

12 Vgl. „Rösler ist von Wahlerfolg der FDP überzeugt“, in: dapd vom 16. März 2012.

13 Vgl. SZ online vom 7. Mai 2012, http://www.sueddeutsche.de/politik/kubicki-lindner-co-die-fdpscheintot-und-aufgeblasen-1.1350410 (Abruf am 4. Juni 2012).

14 Vgl. FAZ online vom 23. April 2012, http://www.faz.net/aktuell/politik/inland/wahlkampf-innrw-woher-die-energie-nehmen-11727838.html (Abruf am 10. Mai 2012).

15 Vgl. Spiegel online vom 8. Mai 2012, http://www.spiegel.de/politik/deutschland/merkel-und-dernrw-wahlkampf-unmut-in-der-cdu-ueber-roettgen-a-832137.html (Abruf am 11. Mai 2012).

16 Vgl. „Ärger über Röttgen“, in: SZ vom 10. Mai 2012, S. 6.

17 FAZ online vom 9. Mai 2012, http://www.faz.net/aktuell/politik/inland/merkel-und-die-landtagswahlen-alles-auslegungssache-11745360.html (Abruf am 10. Mai 2012).

18 Spiegel online vom 7. Mai 2012, http://www.spiegel.de/politik/deutschland/salafisten-gegen-pronrw-hannelore-kraft-will-druck-erhoehen-a-831724.html (Abruf am 5. Juni 2012). 
mit den städtischen Finanzen. ${ }^{19}$ Der Solidarpakt II galt ihnen als „perverses System “20. Zwar verwahrten sich die Vorsitzenden der ostdeutschen SPD-Landtagsfraktionen gegen diesen populistischen Vorstoß. ${ }^{21}$ Hannelore Kraft bot er aber Gelegenheit, zur Mäßigung aufzufordern und doch zugleich ,jetzt sind wir dran“ zu rufen. ${ }^{22}$

\subsection{Landespolitische Faktoren}

Der Grundsatz, dass alle demokratischen Parteien im Grundsatz miteinander koalitionsfähig seien, hatte in Nordrhein-Westfalen reale Gestalt angenommen. Dem entsprach, dass die Parteien während des Wahlkampfes alle Möglichkeiten künftigen Zusammenwirkens diskutierten:

- Für die CDU verkündete deren stellvertretender Landesvorsitzender Armin Laschet, dass sowohl Schwarz-Grün als auch eine Große Koalition denkbar seien. ${ }^{23}$ Spitzenkandidat Röttgen besaß keine „Vorabpräferenz" zugunsten einer Koalition mit der FDP. Diese habe sich der Minderheitsregierung viel zu sehr ,angedient ${ }^{\text {“24. }}$.

- Für die Grünen erklärte deren Landesvorsitzende alle Kombinationen für möglich"25, während der Vorsitzende der grünen Bundestagsfraktion Schwarz-Grün ausschloss. ${ }^{26}$

- Für die FDP erteilte deren Spitzenmann Lindner einer „Ampel“-Koalition mit SPD und Grünen mal eine Absage ${ }^{27}$, mal nicht. ${ }^{28}$

- Für die Linke hielt der Vorsitzende der Bundestagsfraktion Rot- Grün-Rot für möglich, während der Parteivorsitzende diese Kombination ablehnte. ${ }^{29}$

- Die Piratenpartei schloss eine Teilnahme an einer künftigen Landesregierung nicht aus und hielt eine Koalition sowohl mit der SPD als auch mit der CDU für möglich. ${ }^{30}$

19 Vgl. Stefan Bajohr, Beratender Sanierungsmanager in einer hoch verschuldeten Kommune. Ein Erfahrungsbericht aus der Stadt Hagen, in: Verwaltung und Management, 15. Jg. (2009), H. 4, S. $171-186$.

20 Vgl. Spiegel online vom 20. März 2012, http://www.spiegel.de/politik/deutschland/buergermeister -im-ruhrgebiet-wollen-solidarpakt-ost-kuendigen-a-822411.html (Abruf am 11. Mai 2012).

21 Vgl. „Ruhrgebiet hat keine Kohle“, in: Neues Deutschland vom 21. März 2012, S. 1.

22 Interview mit Hannelore Kraft, in: FAZ online vom 30. April 2012, http://www.faz-net./aktuell/ politik/inland/wahl-in-nordrhein-westfalen-2012/hannelore-kraft-im-gespraech-bildung-muss-inder-kita-beginnen-11734253.html (Abruf am 10. Mai 2012).

23 Vgl. „Laschet hält Schwarz-Grün in NRW für möglich“, in: dapd vom 16. März 2012.

24 Vgl. Spiegel online vom 17. März 2012, http://www.spiegel.de/politik/deutschland/parteienbringen-sich -fuer-die-landtagswahl-in-nrw-in-stellung-a-821903.html (Abruf am 11. Mai 2012).

25 Vgl. „NRW-Grüne schließt keine Koalitionsoptionen aus“, in: dapd vom 16. März 2012.

26 Vgl. Spiegel online vom 18. März 2012, a.a.O. (Fn. 11).

27 Vgl. Rheinische Post online vom 11. Mai 2012, http://www.presseportal.de/pm/30621/2250779/ rheinische-post-fdp-spitzenkandidat-lindner-gegen-ampel-koalition-in-nrw (Abruf am 6. Juni 2012).

28 Vgl. Spiegel online vom 2. Mai 2012, http://www.spiegel.de/politik/deutschland/christian-lindner-kritisiert-fdp-fuehrung-a-830899.html (Abruf am 11. Mai 2012).

29 Vgl. „Gysi hält NRW-Koalition mit SPD und Grünen offen“, in: dapd vom 16. März 2012; Frankfurter Rundschau online vom 17. März 2012, http://www.fr-online.de/nrw-wahl/landtagswahl-in-nordrhein-westfalen--linke--kein-rot-rot-gruen-in-nrw.11941226.11920760.html (Abruf am 13. Mai 2012).

30 Vgl. Interview mit Joachim Paul, in: Zeit online vom 16. April 2012, http://www.zeit.de/politik/ deutschland/2012-04/piraten-nrw-joachim-paul/seite-1; „NRW-Spitzenkandidat der Piraten sieht 
- Einzig die sozialdemokratische Spitzenkandidatin legte sich von Anfang an auf eine Fortsetzung von Rot-Grün fest. ${ }^{31}$

Am Wahltag sprachen sich 57 Prozent der Wahlberechtigten für eine rot-grüne Koalition aus. 60 Prozent glaubten nicht, dass eine CDU-geführte Landesregierung die Probleme besser lösen könnte. 39 Prozent präferierten eine Große, 17 Prozent eine schwarz-rote und 13 Prozent eine „Ampel“-Koalition. ${ }^{32}$

Das Hauptproblem der Minderheitsregierung bestand in einem Schuldenberg von rund 127 Milliarden Euro. Knapp elf Prozent der Steuereinnahmen flossen als Zinsausgaben an Kapitalsammelstellen und konnten nicht für gestaltende Politik eingesetzt werden. Um ab 2020 strukturelle Nettokreditaufnahmen auszuschließen, verlangten CDU und FDP drastische Kürzungen des Etats. Dem hielt die Koalition entgegen, dass die „Schuldenbremse“ eine „solide Finanzierung staatlicher Leistungen“ voraussetze. ${ }^{33}$ Ihre „präventive Politik“ werde jetzt Kredite für soziale und bildungspolitische Zwecke aufnehmen, um spätere „gesellschaftliche Reparaturkosten“ zu vermeiden. ${ }^{34}$ Die CDU ernannte die Ministerpräsidentin daraufhin zur „Schuldenkönigin“35.

Als die CDU erkennen musste, dass sie ihr Wahlziel verfehlen würde, entdeckte sie die Gelegenheit, Kraft den Geruch von Vetternwirtschaft anzuhängen: Im Wahlkampf 2010 hatten anonyme Blogger enthüllt, dass Gespräche mit dem damaligen CDU-Ministerpräsidenten gegen Bezahlung angeboten wurden („Sponsorenaffäre“), und sie hatten brisante E-Mails zwischen Staatskanzlei und CDU-Landesverband veröffentlicht. Nun, 2012, stand die Frage im Raum, ob sich die SPD für die seinerzeitige Wahlkampfhilfe in Form öffentlicher Aufträge an die Blogger bedankt hatte. ${ }^{36}$ Die Angelegenheit wurde nicht mehr vor dem Wahltag aufgeklärt.

\section{Der Wahlkampf}

Der Wahlkampf begann, als das Ergebnis der Abstimmung über die Auflösung des Landtags feststand. Infratest dimap ermittelte, dass die Wirtschaftspolitik (32 Prozent), soziale Gerechtigkeit (31), Bildungs- (30) und Arbeitsmarktpolitik (20) nach Ansicht der Wahlberechtigten die entscheidenden Themen des Parteienwettbewerbs waren. ${ }^{37}$ Laut Forschungs-

Möglichkeiten zum Mitregieren“, in: WDR.de vom 28. April 2012, http://www1.wdr.de/themen/ infokompakt/nachrichten/nrwkompakt/archiv/nrwkompakt5820.html (Abrufe am 20. Juni 2012).

31 Vgl. Spiegel online vom 15. März 2012, http://www.spiegel.de/politik/deutschland/norbert-roettgen-tritt-bei-nrw-landtagswahl-gegen-hannelore-kraft-an-a-821626.html (Abruf am 11. Mai 2012).

32 Vgl. infratest dimap, Landtagswahl Nordrhein-Westfalen 2012. Umfragen, http://stat.tagesschau. de/wahlen/2012-05-13-LT-DE-NW/index.shtml (Abruf am 20. Mai 2012).

33 Vgl. Landtag Nordrhein-Westfalen, Plenarprotokoll 15/50 vom 21. Dezember 2011, S. 5040.

34 Vgl. Spiegel online vom 17. März 2012, http://www.spiegel.de/deutschland/nrw-finanzpolitikstreit-um-haushalt-und-neuverschuldung-a-821861.html (Abruf am 11. Mai 2012).

35 Vgl. Rheinische Post online vom 17. April 2012, http://www.rp-online.de/politik/nrw/norbertroettgen-jagt-die-schulden-koenigin-1.2795268 (Abruf am 10. Mai 2012).

36 Vgl. ebenda vom 9. Mai 2012, http://www.rp-online.de//politik/nrw/kraft-regierung-wehrt-sichgegen-vorwurf-1.2824646 (Abruf am 10. Mai 2012).

37 Vgl. infratest dimap, Landtagswahl Nordrhein-Westfalen 2012. Umfragen, http://stat.tagesschau. de/wahlen/2012-05-13-LT-DE-NW/index.shtml (Abruf am 20. Mai 2012). 
gruppe Wahlen erreichten Schule und Bildung sowie Verschuldung und Finanzen jeweils 28 Prozent, während das Thema Arbeitslosigkeit auf 25 Prozent kam. ${ }^{38}$

Hinsichtlich zugeschriebener Kompetenzen fiel der Vorsprung der SPD beim Thema soziale Gerechtigkeit deutlich aus; er war aber nicht überraschend. Auch vor den Landtagswahlen von 2010, 2005 und 2000 lag sie bei diesem Thema vorn. Wie schon 2000 und 2010 führte die SPD auch in Sachen Schule und Bildung. Im Kontrast zum relativ guten Abschneiden der CDU bei den Selbstständigen erkannten die Wähler dieses Mal der SPD größere wirtschaftspolitische Kompetenz zu. Demgegenüber blieb die CDU in Sachen Finanzkompetenz, unter anderem wegen ihrer Klage vor dem Verfassungsgerichtshof und der darauf aufbauenden Wahlkampagne, in Führung. Auch trauten die Wähler der CDU am ehesten zu, für Arbeitsplätze zu sorgen. ${ }^{39}$

Der unerwartet einsetzende Wahlkampf verursachte personelle Umbesetzungen an der Spitze einiger Parteien:

- Die Piratenpartei ließ ihren Landesvorsitzenden Michele Marsching durchfallen. Anstatt auf Platz eins setzte sie ihn auf Platz vier der Landesliste. Platz eins errang mit einer knappen Mehrheit von 50,8 Prozent der Politneuling Joachim Paul.

- Die Linke setzte die Landesvorsitzende Katharina Schwabedissen auf Platz eins der Landesliste anstelle von Bärbel Beuermann, die neben Wolfgang Zimmermann die Landtagsfraktion führte.

- Bei der FDP überließ Bundesgesundheitsminister Daniel Bahr Spitzenkandidatur und Landesvorsitz dem abgetretenen Generalsekretär Christian Lindner.

Spitzenkandidatin der Grünen wurde erwartungsgemäß Vizeministerpräsidentin Sylvia Löhrmann. Die SPD bestätigte Ministerpräsidentin Kraft als Spitzenkandidatin. Die CDU nominierte ihren Landesvorsitzenden Röttgen zum Kandidaten für die Staatskanzlei.

Der Wahlkampf war stark personalisiert. Vor allem SPD und FDP fokussierten ihre Wahlwerbung auf die Medienlieblinge Kraft und Lindner. Wahlprogramme spielten eine untergeordnete Rolle. FDP und CDU unterzogen sich nicht einmal der Mühe, Programme vorzulegen, sondern stellten Wahlaufrufe im Umfang von fünf beziehungsweise 17 Seiten ins Netz. Den Grünen reichte ein „update“ ihres Landtagswahlprogramms von 2010. Die SPD begnügte sich mit einem Wahlprogramm von 21 Seiten. Allein die Linke und die Piratenpartei präsentierten Wahlprogramme von 68 beziehungsweise 76 Seiten Länge.

Die SPD wollte vor allem als „Kümmererpartei“ in Erscheinung treten. ${ }^{40}$ „Ich bleibe in NRW, ich habe meine Aufgabe hier und mein Herz hängt an NRW“41, erklärte Kraft. Aufsehen erregte das politikfreie Plakat „Currywurst ist SPD“, das aus einem Internetwettbewerb hervorgegangen war. Inhaltlich sprach sich die SPD für „eine angemessene Besteuerung großer Vermögen und Erbschaften“, die Wiederanhebung des Spitzensteuersatzes der Einkommensteuer

38 Vgl. Politbarometer Extra NRW vom 4. Mai 2012, http://www.zdf.de/ZDF/zdfportal/web/ZDF. de/Politbarometer/2942200/21769826/872f68/Knappe-Mehrheit-für-Rot-Grün--FDP-bei-sechsProzent.html (Abruf am 6. Juni 2012).

39 Vgl. Forschungsgruppe Wahlen, Wahl in Nordrhein-Westfalen. Eine Analyse der Landtagswahl vom 13. Mai 2012, Mannheim 2012, S. 29, S. 31.

$40 \mathrm{Vgl}$. FAZ online vom 30. April 2012, http://www.faz.net/aktuell/politik/inland/wahl-in-nordrhein-westfalen-2012/spd-in-nordrhein-westfalen-prozess-der-enthartzung-11735123.html (Abruf am 10. Mai 2012).

41 Vgl. „Mit ganzer Kraft für NRW“, in: dapd vom 15. März 2012. 
und für eine Finanztransaktionssteuer aus. ${ }^{42}$ Mehreinnahmen hieraus wollte sie aber nicht zur Senkung der Nettoneuverschuldung einsetzen, sondern in „Kinder, Bildung, Vorbeugung und in die Handlungsfähigkeit unserer Kommunen“ investieren. ${ }^{43}$ Wenn „kein Kind zurück[ge] lassen“ werde, könne auch die „Schuldenbremse“ eingehalten werden. Die SPD wollte den Rechtsanspruch unter Dreijähriger auf einen Kita-Platz erfüllen und die Beitragsfreiheit über das dritte Kindergartenjahr hinaus ausweiten. Als gesellschaftspolitische Ziele nannte sie soziale Gerechtigkeit, Teilhabe und Aufstiegschancen. Wirtschaftspolitisch bekannte sie sich zur Industrie und zum „Klimaschutz als Fortschrittsmotor“. Im Vordergrund der Energiepolitik sollten Effizienz, Speichertechnologien und der Ausbau erneuerbarer Energien stehen, konventionelle Kohlekraftwerke aber „für eine Übergangszeit“ weiterbetrieben werden. ${ }^{44}$

Die CDU wollte Politik „aus den Augen der Kinder“ machen. ${ }^{45}$ Sie kritisierte, dass Nordrhein-Westfalen bei den U3-Plätzen im Ländervergleich den letzten Platz einnehme ${ }^{46}$, verwahrte sich aber gegen eine Kita-Pflicht. Die Ministerpräsidentin bringe ein „verqueres Menschenbild“ (Bundesfamilienministerin Kristina Schröder) zum Ausdruck ${ }^{47}$, wenn sie verlange, „dass alle Kinder“ in der Kita „sind, statt eine Prämie für Kinder zu zahlen, damit sie fernbleiben “ 48 . Schulpolitisch hielt sich die CDU den Schulkonsens und die Erhaltung des gegliederten Schulsystems zugute. Haushaltspolitisch wollte Röttgen die Neuverschuldung auf null zurückführen. Dazu passte allerdings nicht, dass er eine Wiedereinführung von Studiengebühren sowie die Beseitigung der Beitragsfreiheit für das dritte Kindergartenjahr aus dem Konsolidierungsplan der CDU-Landtagsfraktion entfernte und dass er - gegen das Votum des christdemokratischen Bundesfinanzministers - die FDP-Forderung nach Anhebung der Pendlerpauschale unterstützte. Er versprach Einsparungen, vermied aber jede Festlegung. Energiepolitisch sprach sich die CDU für die Kohleverstromung aus und zwang Röttgen zum Spagat zwischen der von ihm als Bundesumweltminister zu realisierenden Energiewende einerseits und der dünnen Bilanz der schwarz-gelben Landesregierung (2005 bis 2010) in Sachen erneuerbare Energien andererseits.

Als Bürde für den christdemokratischen Wahlkampf sollte es sich erweisen, dass Röttgen sich nicht klar zu seiner politischen Zukunft äußerte. Bereits am Tage der Landtagsauflösung war er der Frage ausgewichen, ob er auch als Oppositionsführer nach Düsseldorf gehen würde. ${ }^{49}$ Obgleich Parteifreunde ihn drängten, nicht ausschließlich auf die Karte des Ministerpräsidenten zu setzen, beharrte er darauf, dass die Partei entscheide, wo sein Platz sei, wenn die CDU am Wahlabend nicht vorn liegen sollte. ${ }^{50}$ Selbst gegenüber Angela Merkel

42 NRWSPD, NRW auf gutem Weg. Regierungsprogram der NRWSPD 2012-2017, S. 4, http:// www.nrwspd.de/db/docs/doc_39304_201246152712.pdf (Abruf am 10. Mai 2012).

43 Vgl. Landtag Nordrhein-Westfalen, a.a.O. (Fn. 3), S. 5712.

44 Vgl. NRWSPD, a.a.O. (Fn. 42), S. 4 f., S. 10.

45 Vgl. Spiegel online vom 17. März 2012, a.a.O. (Fn. 34).

46 Vgl. CDU NRW, Verantwortung, Kompetenz. Nachhaltigkeit. Wahlaufruf an die Bürgerinnen und Bürger in Nordrhein-Westfalen, S. 12, http://wahl2012.cdu-nrw.de/wp-content/uploads/2012/04/LTW_Wahlaufruf.pdf (Abruf am 10. Mai 2012).

47 Vgl. Focus online vom 29. April 2012, http://www.focus.de/politik/deutschland/union-tobthannelore-kraft-alle-kinder-muessen-in-die-kita_aid_744962.html (Abruf am 6. Juni 2012).

48 Interview mit Hannelore Kraft, a.a.O. (Fn. 22).

49 Vgl. „Röttgen kritisiert FDP in NRW“, in: dapd vom 14. März 2012.

50 Vgl. SZ online vom 15. März 2012, http://www.sueddeutsche.de/politik/neuwahl-in-nordrheinwestfalen-parteifreunde-verlangen-von-roettgen-bekenntnis-zu-nrw-1.1310183 (Abruf am 11. Mai 2012). 
lehnte er es ab, sich zu einem Wechsel nach Düsseldorf zu verpflichten. ${ }^{51}$ Dies machte auf Wahlberechtigte den Eindruck, dass er sich einen Verbleib im Amt des Bundesumweltministers offenhielt und die Spitzenkandidatur nur als karrierefördernde Zwischenstation auf dem Weg ins Bundeskanzleramt verstand. Für seine Absicherungsstrategie sprach, dass zwischen den Erfolgsaussichten bei einer Landtagswahl und der Bereitschaft, eine wichtige Funktion im Bund gegen eine Oppositionsbank im Land einzutauschen, keine Kausalität zu bestehen scheint. Dennoch hinterließ Röttgens Taktieren eine weithin ungünstige Wirkung. Rösler unterstellte ihm, kein Interesse an Nordrhein-Westfalen zu haben..$^{52}$ Lindner versprach, sein Bundestags- gegen ein Landtagsmandat einzutauschen ${ }^{53}$, und Hannelore Kraft sah ihren Platz ausschließlich in Düsseldorf - als Ministerpräsidentin oder als Oppositionsführerin. ${ }^{54}$ Eine spätere Kanzlerkandidatur schloss sie aus. ${ }^{55}$

Eine weitere Ungeschicklichkeit leistete sich der CDU-Spitzenkandidat in der Fernsehsendung „Log in“ im ZDF Info. Auf den Vorhalt der Moderatorin, er müsse, wenn er „das Beste für das Land“ wolle, „auch in die Opposition gehen“, erwiderte Röttgen holperig, das müsse er nicht, sondern „,ich müsste dann eigentlich Ministerpräsident werden. [...] Bedauerlicherweise entscheidet nicht allein die CDU darüber, sondern die Wähler entscheiden darüber.“ Als der Ko-Moderator nachhakte: „Bedauerlicherweise?“, war die Partie für Röttgen verloren. ${ }^{56}$

Die Grünen setzten haushalts- und finanzpolitisch auf einen Dreiklang aus Konsolidierung (ohne sich auf Einzelheiten festlegen zu lassen), Investitionen in Bildung, Kita-Plätze und Klimaschutz sowie „eine andere Steuerpolitik auf Bundesebene "57. Pfiffig plakatierten sie, es wäre „schön, wenn Frauen“, also Kraft und Löhrmann, „wieder den Haushalt machen “58. Bildungspolitisch wollten sie wie die SPD „kein Kind zurücklassen“, und sie nahmen für sich in Anspruch, das Bildungssystem gerechter gemacht zu haben. Wirtschaftspolitisch schränkten sie das Bekenntnis von SPD und CDU zum „Industriestandort“ Nordrhein-Westfalen dahingehend ein, dass dieser eines ökologischen und klimapolitischen Umbauprozesses bedürfe. Die Grünen sprachen sich gegen Kohlekraftwerke als „Brückentechnologie“ aus. ${ }^{99}$ Getrübt wurde ihre Glaubwürdigkeit dadurch, dass die Dominanz klimaschädigender Kohleverstromung in zwölf Jahren grüner Regierungsbeteiligung nicht abgebaut worden war und Nordrhein-Westfalen in Bezug auf die erneuerbaren Energien Platz zwölf im Ländervergleich belegt.

51 Vgl. Spiegel online vom 18. März 2012, a.a.O. (Fn. 11).

52 Vgl. SZ online vom 18. März 2012, http://www.sueddeutsche.de/politik/wahlkampf-in-nrwschwarz-gelbe-sticheleien-1.1311852 (Abruf am 11. Mai 2012).

53 Vgl. Spiegel online vom 19. März 2012, http://www.spiegel.de/politik/deutschland/fdp-sticheltgegen-roettgen-a-822315.html (Abruf am 11. Mai 2012).

54 Vgl. ebenda vom 15. März 2012, a.a.O. (Fn. 31).

55 Vgl. ebenda vom 17. März 2012, a.a.O. (Fn. 24).

56 Vgl. http://www.youtube.com/watch?v=owST6KHn4_o (Abruf am 12. Mai 2012).

57 Die Welt online vom 19. März 2012, http://www.welt.de/politik/wahl/nrw-wahl/article13929333/ Wir-definieren-uns-nicht-ueber-Rot-Gruen.html (Abruf am 11. Mai 2012).

58 Vgl. SZ online vom 14. April 2012, http://www.sueddeutsche.de/politik/wahlkampf-in-nrwlindner-flirtet-mit-der-spd-1.1332590 (Abruf am 11. Mai 2012).

59 Vgl. Bündnis 90/Die Grünen NRW, Zukunftsplan für NRW. Das Programm zur Landtagswahl 2010, Update 2012, S. 12 f., S. 21 ff., http://www.gruene-nrw.de/zukunftsplan.html (Abruf am 10. Mai 2012). 
Die FDP wurde auf einer Welle medialer Promotion aus den Umfragetiefs über die Fünfprozenthürde getragen. ${ }^{60}$ Keine überregionale Zeitung, keine der großen Rundfunkanstalten ließ es sich nehmen, einen Starrummel um den freidemokratischen Spitzenkandidaten zu veranstalten. Die Medien störte nicht einmal, dass Lindner sich in die „Tradition“ des wegen Steuerhinterziehung rechtskräftig verurteilten Otto Graf Lambsdorff stellte. ${ }^{61}$

Ohne zu konkretisieren, an welcher Stelle des Landeshaushalts die FDP einsparen wollte, prangerte die FDP die Verschuldung an und forderte den „schlanken“ Staat. ${ }^{62}$ Er dürfe „nicht mehr schneller wachsen, als wir Wohlstand erwirtschaften"63, postulierte Lindner, obgleich das Wachstum der Steuereinnahmen seit Jahrzehnten hinter dem Wirtschaftswachstum zurückbleibt. Geschickt deutete Lindner das rechtsirrige Nein vor der zweiten Lesung des Landeshaushalts in politische Standfestigkeit um: „Lieber neue Wahlen als neue Schulden. "64 Dies war ein gewagter Slogan, denn die Wahlplakate, auf denen die FDP behauptete „Wir können auch ohne Schulden“, waren kreditfinanziert. ${ }^{65}$ Energiepolitisch ließ sich die FDP von dem Kohlelobbyisten Wolfgang Clement beraten, der früher einmal SPDMinisterpräsident gewesen war. Bildungspolitisch sprach sie sich im Widerspruch zu liberalen Gleichheitsgrundsätzen gegen den Schulkonsens und für das ständisch gegliederte, Kinder aus unterbürgerlichen Schichten benachteiligende Schulsystem aus. ${ }^{66}$ Studiengebühren sollten wieder eingeführt werden. ${ }^{67}$

Gänzlich anders als für die FDP stellte sich die mediale Aufmerksamkeit für die Linke dar: Nicht selten wurde sie regelrecht ausgegrenzt. So fand in Düsseldorf ein Gespräch von Chefredakteuren deutscher Regionalzeitungen mit den Spitzenkandidat/innen der nordrhein-westfälischen Landtagswahl statt, zu dem die Kandidatin der Linken nicht eingeladen worden war. ${ }^{68}$ Das regionale Fenster des Privatsenders RTL lud zwar vier im Landtag vertretene Parteien und sogar die nicht im Landtag vertretene Piratenpartei zur Präsentation ihrer Programme ein, nicht aber die Landtagspartei Die Linke. ${ }^{69}$ Selbst noch am Wahlabend hatte ARD-Unterhalter Günter Jauch die Bundesvorsitzenden von SPD und FDP, eine stell-

60 Vgl. NachDenkSeiten vom 16. April 2012, http://www.nachdenkseiten.de/?p=12870; NachDenkSeiten vom 23. April 2012, http://www.nachdenkseiten.de/?p=1294 (Abrufe am 10. Mai 2012).

61 Vgl. „An Koalitionen will er noch nicht denken“, in: Aachener Nachrichten vom 13. April 2012, S. 4.

62 Vgl. Welt online vom 25. April 2012, http://www.welt.de/politik/deutschland/article106226882/ Wir-machen-in-Nordrhein-Westfalen-die-neue-FDP.html (Abruf am 26. April 2012).

63 Interview mit Christian Lindner, in: SZ online vom 8. Mai 2012, http://www.sueddeutsche.de/ politik/2.220/fdp-spitzenkandidat-lindner-zur-nrw-wahl-das-cdu-modell-ist-so-vage-dass-es-vonden-piraten-sein-koennte-1.1351527 (Abruf am 11. Mai 2012).

64 Interview mit Christian Lindner, in: Spiegel online vom 3. April 2012, http://www.spiegel.de/ politik/deutschland/interview-mit-fdp-hoffnungstraeger-christian-lindner-a-825296.html (Abruf am 11. Mai 2012).

65 Vgl. „Schärfere Töne. Vorlaute Liberale, starke Piraten, nervöse Rot-Grüne - der NRW-Wahlkampf gewinnt an Fahrt", in: Der Tagesspiegel vom 4. Mai 2012, S. 4.

66 Vgl. Welt online vom 15. März 2012, http://www.welt.de/politik/deutschland/article13922751/ FDP-ist-gut-aufgestellt-fuer-den-Spontanwahlkampf.html (Abruf am 10. Mai 2012).

67 Vgl. Welt online vom 31. März 2012, http://www.welt.de/politik/deutschland/article106141742/ Lindner-will-Studenten-in-NRW-zur-Kasse-bitten.html (Abruf am 2. Juni 2012).

$68 \mathrm{Vgl}$. „Und doch sind sie alle irgendwie unverwechselbar“, in: Aachener Zeitung vom 5. Mai 2012, S. 25.

69 Vgl. Der Westen online vom 24. April 2012, http://www.derwesten.de/nachrichten/linke-wirftrtl-ausgrenzung-bei-der-wahlberichterstattung-vor-id6589844.html (Abruf am 26. April 2012). 
vertretende CDU-Bundesvorsitzende sowie den Vorsitzenden der grünen Bundestagsfraktion zu Gast, aber niemanden von den ebenfalls im Bundestag vertretenen Linken. ${ }^{70}$

Doch es war nicht der mediale Gegenwind allein, der der Linken den Wahlkampf schwer machte. Hinzu kam, dass es ihrer Landtagsfraktion nicht gelungen war, sich mit eigenständigen Konzepten für die Landespolitik zu profilieren. Zu oft hatte sie sich darauf beschränkt, Mehrheiten für die Minderheitsregierung zu ermöglichen oder zu verhindern. Geradezu existenzbedrohend war, dass die Ministerpräsidentin den Linken die Kompetenzfelder Arbeitsmarkt- und Sozialpolitik streitig machte. Weil Kraft sich geschickt von der Agenda 2010 distanzierte, die sie als Landesministerin (2001 bis 2005) mitgetragen hatte, erschien die Landes-SPD vielen Bürgern wieder als sozial ausgewogen und die Linke mithin als entbehrlich. Deren These, dass die Minderheitsregierung soziale Verbesserungen nur wegen des Drängens der Linken beschlossen habe, verfing nicht.

Die Linke wollte große Einkommen und Vermögen stärker zur Finanzierung öffentlicher Aufgaben heranziehen: „Unsere Schuldenbremse heißt Millionärssteuer" ${ }^{\text {"71, }}$, denn Staatsschulden seien „die nicht gezahlten Steuern der Reichen“72. Sie mahnte den Ausbau von Kita-Plätzen an und widersprach der Behauptung, das Schulsystem sei gerechter geworden. Die Linke wollte Energiekonzerne in öffentliches Eigentum überführen. Wie die Grünen plädierte sie für den Ausstieg aus der Kohleverstromung. Arbeitsmarktpolitisch forderte sie ein Konjunkturprogramm, Arbeitszeitverkürzungen, mehr öffentliche Investitionen, mehr Beschäftigung im öffentlichen Dienst und ein Verbot von Leiharbeit. ${ }^{73}$

Die Piratenpartei verursachte bei den Parlamentsparteien allein durch ihr Auftreten und ihren antizipierten Wahlerfolg Unsicherheit und Unbehagen. Wohlwollen genoss sie indes bei den Medien. Deren Umgang mit den Piraten unterschied sich merklich von der Behandlung der frühen Grünen und der PDS beziehungsweise der Linken. Programmatisch hatten sich die Piraten in vielerlei Hinsicht noch nicht entschieden. Allein das Stichwort „Transparenz" durchzog nahezu sämtliche Punkte des Wahlprogramms. Wirtschaftspolitisch sprachen sie sich dafür aus, „Monopole und Oligopole durch die Schaffung transparenter Marktstrukturen aufzulösen". Wie die Linke unterstrich die Piratenpartei die Sozialpflichtigkeit des Eigentums. Zur Verschuldungsproblematik und zur Haushaltspolitik schwieg das Wahlprogramm. Energiepolitisch setzten die Piraten auf die Dezentralisierung der Strom- und Wärmeerzeugung und den Vorrang von Gas- vor Kohlekraftwerken. Bildungspolitische Vision seien eine „beitragsfreie Ganztagsbetreuung in wohnortnahen Kindertagesstätten“ und kleinere Klassen. ${ }^{74}$ Der Landesvorsitzende erklärte, „keine Fundamentalopposition betreiben, sondern da mitmachen“ zu wollen, „wo wir es inhaltlich vertreten können“75.

70 Vgl. die Teilnehmer in der Sendung Günter Jauch vom 13. Mai 2012 (Liste der Teilnehmer durch E-Mail der ARD-Programmdirektion vom 12. Juni 2012 an den Verfasser bestätigt).

71 Vgl. „Drei mal drei statt Katerstimmung“, in: Neues Deutschland vom 19. März 2012, S. 5.

72 Vgl. Rheinische Post online vom 11. Mai 2012, http://www.rp-online.de/politik/nrw/linksparteiwettert-gegen-die-grossen-parteien-1.2828913 (Abruf am 13. Mai 2012).

73 Vgl. Die Linke, Original sozial - konsequent solidarisch. Das Landeswahlprogramm 2012, Bochum 2012, S. 2, S. 16, S. 29, S. 39, http://www.dielinke-nrw.de/fileadmin/kvwebsites.material/ Wahlprogramme/linkenrw_ltw2012-langwahlprogramm_WEB.pdf (Abruf am 10. Mai 2012).

74 Vgl. Piraten, Dafür, dass wir keins haben, steht hier viel drin. Wahlprogramm, Dortmund 2012, S. 8 f., S. 11, S. 26 f., S. 38, S. 66, S. 68, https://wiki.piratenpartei.de/wiki/images/b/bf/WahlprogrammNRW2012_Basis_V2_PrintA5.pdf (Abruf am 10. Mai 2012).

75 „Wir werden viele Fehler machen. Interview mit Joachim Paul“, in: dapd vom 8. Mai 2012. 


\section{Das Wahlergebnis}

Das Ergebnis der Landtagswahl überraschte, was die CDU und ihren Spitzenkandidaten anging, nicht. Auch das Ausscheiden der Linken und der Einzug der Piratenpartei waren erwartet worden. Die Spannung am Wahlabend konzentrierte sich auf die Frage, ob RotGrün eine eigene Mehrheit bekommen und ob die FDP im Landtag bleiben würde.

Der Wahlausgang dokumentierte das Scheitern der Wahlrechtsreform von 2005, die unter anderem eine deutliche Verringerung der Zahl der Mandate bringen sollte. Weil die SPD aber 99 Wahlkreise (2010: 61; 2005: 39) eroberte, mussten deren Überhangmandate ausgeglichen werden. Damit erhöhte sich die Zahl der Abgeordneten von gesetzlich vorgesehenen 181 auf 237. In der 67-köpfigen CDU-Fraktion vertreten nur 29 Abgeordnete einen gewonnenen Wahlkreis (2010: 67; 2005: 89).

Mit 39,1 Prozent der Zweitstimmen für die SPD und 11,3 Prozent für die Grünen war das Wahlziel beider Parteien, eine eigene Mehrheit zu erringen, erreicht. Das Wahlergebnis fiel für die SPD deutlich besser aus als 2010 und 2005. Dennoch war das Resultat weniger gut als bei allen Landtagswahlen zwischen 1958 und 2000.

Für die CDU war das Wahlergebnis „ein Keulenschlag“76. Sie verlor 38 Direktwahlkreise und errang nur 26,3 Prozent der Zweitstimmen. Dies war ihr schlechtestes Ergebnis seit 1947. Gegenüber 2010 verlor sie noch einmal 600.000 Stimmen oder 8,3 Prozentpunkte. Zum Teil mag sich dieser Misserfolg aus dem „antigouvernementalen Effekt“ erklären, dem Parteien, die im Bund regieren, bei Landtagswahlen ausgesetzt sind. ${ }^{77}$ Auf dem Hintergrund noch schlechterer CDU-Ergebnisse in anderen Ländern könnte man ihn sogar relativieren. Die Niederlage erklärte sich aber auch aus dem verfehlten Wahlkampfkonzept und den Schwächen des Spitzenkandidaten, der nach Veröffentlichung der ersten Hochrechnungen seinen Rücktritt als CDU-Landesvorsitzender bekanntgeben musste. ${ }^{78}$

Die Grünen wollten im März bei einer Neuwahl „,noch etwas drauflegen“79. Im April wurde indessen erkennbar, dass die Partei schwächelte. Im Mai büßte sie, verglichen mit 2010, rund 57.000 Zweitstimmen beziehungsweise 0,8 Prozentpunkte ein. Dennoch handelte es sich um das zweitbeste Landtagswahlergebnis in Nordrhein-Westfalen seit Gründung der Partei.

Die FDP verdankte ihren Wiedereinzug in den Landtag vor allem der breiten medialen Unterstützung für ihr Fortleben und ihren vermeintlich „frischen “ Spitzenkandidaten sowie der schlechten Vorstellung der CDU. 160.000 Wähler, die noch 2010 für die CDU votiert hatten, waren zur FDP abgewandert.

76 Peter Altmaier, Geschäftsführer der CDU/CSU-Bundestagsfraktion, zitiert in: Kraft triumphiert. Desaster für CDU - Norbert Röttgen tritt zurück, in: Rheinische Post vom 14. Mai 2012, S. 1.

77 Vgl. Rainer-Olaf Schultze, Wählerverhalten und Parteiensystem in der Bundesrepublik Deutschland, in: Landeszentrale für politische Bildung Baden-Württemberg (Hrsg.), Westeuropas Parteiensysteme im Wandel, Stuttgart 1983, S. 6 - 44, S. 12.

78 Zum Nachfolger wählte die CDU am 30. Juni 2012 Armin Laschet. Bei den Piraten trat der Soester Softwareentwickler Sven Sladek an die Stelle von Michele Marsching. Bei der Linken folgten die bisherigen Landtagsabgeordneten Gunhild Böth und Rüdiger Sagel auf Katharina Schwabedissen und Hubertus Zdebel.

79 Sylvia Löhrmann, in: Die Welt online vom 19. März 2012, http://www.welt.de/politik/wahl/nrwwahl/article13929333/Wir-definieren-uns-nicht-ueber-Rot-Gruen.html (Abruf am 11. Mai 2012). 


\begin{tabular}{|c|c|c|c|c|c|}
\hline \multicolumn{6}{|c|}{ Tabelle 1: Amtliche Endergebnisse von Landtagswahlen in Nordrhein-Westfalen } \\
\hline \multirow[b]{2}{*}{ Absolute Zahlen } & \multicolumn{2}{|c|}{ 13. Mai 2012} & \multirow{2}{*}{$\begin{array}{c}\text { Zweitstimmen } \\
\text { Differenz } \\
\text { 2012-2010 }\end{array}$} & 9. Mai 2010 & 22. Mai 2005 \\
\hline & Erststimmen & Zweitstimmen & & \multicolumn{2}{|c|}{ Zweitstimmen } \\
\hline Wahlberechtigte & \multicolumn{2}{|c|}{13.262 .049} & -5.003 & 13.267 .052 & 13.230 .366 \\
\hline Wähler/innen & \multicolumn{2}{|c|}{7.901 .268} & 30.856 & 7.870 .412 & 8.333 .363 \\
\hline Gültige Stimmen & 7.780 .610 & 7.793 .995 & 33.449 & 7.760 .546 & 8.244 .014 \\
\hline $\mathrm{CDU}$ & 2.545 .309 & 2.050 .321 & 631.379 & 2.681 .700 & 3.696 .506 \\
\hline SPD & 3.290 .561 & 3.049 .983 & 374.165 & 2.675 .818 & 3.058 .988 \\
\hline B 90/Grüne & 723.581 & 884.298 & 56.864 & 941.162 & 509.293 \\
\hline FDP & 372.727 & 670.082 & 147.853 & 522.229 & 508.266 \\
\hline Die Linke & 201.637 & 194.428 & -241.199 & 435.627 & 254.977 \\
\hline Piratenpartei & 617.926 & 609.176 & 488.130 & 121.046 & - \\
\hline Pro NRW & - & 118.326 & 10.850 & 107.476 & - \\
\hline NPD & - & 40.007 & 15.393 & 55.400 & 73.969 \\
\hline Sonstige & 28.869 & 177.374 & $-42,714$ & 220.088 & 141.336 \\
\hline Anteile & \multicolumn{2}{|c|}{ Prozent* } & Prozentpunkte & \multicolumn{2}{|c|}{ Prozent } \\
\hline Wahlbeteiligung & \multicolumn{2}{|c|}{59,6} & 0,3 & 59,3 & 63,0 \\
\hline $\mathrm{CDU}$ & 32,7 & 26,3 & $-8,3$ & 34,6 & 44,8 \\
\hline SPD & 42,3 & 39,1 & 4,6 & 34,5 & 37,1 \\
\hline B 90/Grüne & 9,3 & 11,3 & $-0,8$ & 12,1 & 6,2 \\
\hline FDP & 4,8 & 8,6 & 1,9 & 6,7 & 6,2 \\
\hline Die Linke & 2,6 & 2,5 & $-3,1$ & 5,6 & 3,1 \\
\hline Piratenpartei & 7,9 & 7,8 & 6,3 & 1,6 & - \\
\hline Pro NRW & - & 1,5 & 0,1 & 1,4 & - \\
\hline NPD & - & 0,5 & $-0,2$ & 0,7 & 0,9 \\
\hline Sonstige & 0,2 & 2,1 & $-0,7$ & 2,8 & 1,7 \\
\hline Sitzverteilung & \multicolumn{2}{|c|}{ Sitze } & $\begin{array}{c}\text { Differenz } \\
\text { 2012-2010 }\end{array}$ & \multicolumn{2}{|c|}{ Sitze } \\
\hline Insgesamt & \multicolumn{2}{|c|}{237} & 56 & 181 & 187 \\
\hline $\mathrm{CDU}$ & \multicolumn{2}{|c|}{67} & 0 & 67 & 89 \\
\hline SPD & \multicolumn{2}{|r|}{99} & 32 & 67 & 74 \\
\hline B 90/Grüne & \multicolumn{2}{|r|}{29} & 6 & 23 & 12 \\
\hline FDP & \multicolumn{2}{|r|}{22} & 9 & 13 & 12 \\
\hline Die Linke & \multicolumn{2}{|r|}{ - } & -11 & 11 & - \\
\hline Piratenpartei & \multicolumn{2}{|r|}{20} & 20 & - & - \\
\hline $\begin{array}{l}\text { * Abweichung vo } \\
\text { Quelle: http://wy } \\
\text { Berechnungen. }\end{array}$ & Prozent d & $\begin{array}{l}\text { Rundungen. } \\
\text { N.de/landtagsw }\end{array}$ & lindex html & am 10. & 012); eigene \\
\hline
\end{tabular}

Der Erfolg der Piratenpartei könnte darauf hindeuten, dass sich in der Bundesrepublik auf Dauer ein Fünf- bis Sechs-Fraktionen-System herausbildet. Denkbar ist aber auch, dass Parteien wie in den 1950er Jahren wieder aus den Parlamenten herausgewählt und bedeutungslos werden, dass sich also die jetzige Vielfalt wieder zurückbildet. Am Wahlabend waren die Piraten dennoch zuversichtlich, sich auf Dauer im Landtag einrichten zu können. 


\begin{tabular}{|c|c|c|c|c|c|c|c|c|c|}
\hline & & \multicolumn{2}{|c|}{2012} & \multicolumn{2}{|c|}{2010} & \multicolumn{2}{|c|}{2005} & \multicolumn{2}{|c|}{2000} \\
\hline & & $\mathrm{m}$ & $\mathrm{w}$ & $\mathrm{m}$ & $\mathrm{w}$ & $\mathrm{m}$ & $\mathrm{w}$ & $\mathrm{m}$ & $\mathrm{w}$ \\
\hline \multirow{2}{*}{ Landtag } & Sitze & 167 & 70 & 132 & 49 & 136 & 51 & 159 & 72 \\
\hline & in $\%$ & 70,5 & 29,5 & 72,9 & 27,1 & 72,7 & 27,3 & 68,8 & 31,2 \\
\hline \multirow{2}{*}{ SPD } & Sitze & 66 & 33 & 48 & 19 & 43 & 31 & 64 & 38 \\
\hline & in $\%$ & 67,0 & 33,0 & 71,6 & 28,4 & 58,1 & 41,9 & 62,7 & 37,3 \\
\hline \multirow{2}{*}{$\mathrm{CDU}$} & Sitze & 52 & 15 & 57 & 10 & 78 & 11 & 69 & 19 \\
\hline & in $\%$ & 77,6 & 22,4 & 85,1 & 14,9 & 90,9 & 9,1 & 78,4 & 21,6 \\
\hline \multirow{2}{*}{ Grüne } & Sitze & 14 & 15 & 11 & 12 & 6 & 6 & 8 & 9 \\
\hline & in $\%$ & 48,3 & 51,7 & 47,8 & 52,2 & 50,0 & 50,0 & 47,1 & 52,9 \\
\hline \multirow{2}{*}{ FDP } & Sitze & 18 & 4 & 11 & 2 & 9 & 3 & 18 & 6 \\
\hline & in $\%$ & 81,8 & 18,2 & 84,6 & 15,4 & 75,0 & 25,0 & 75,0 & 25,0 \\
\hline \multirow{2}{*}{ Linke } & Sitze & & & 5 & 6 & & & & \\
\hline & in $\%$ & & & 45,5 & 54,5 & & & & \\
\hline \multirow{2}{*}{ Piraten } & Sitze & 17 & 3 & & & & & & \\
\hline & in $\%$ & 85,0 & 15,0 & & & & & & \\
\hline
\end{tabular}

Die provokativen antimuslimischen Inszenierungen bescherten ProNRW nur marginale Zugewinne. Zusammen mit der NPD verloren sie rund 4.500 Zweitstimmen und kamen auf nur zwei Prozent. ProNRW kann allerdings aus dem Wahlergebnis einen Anspruch auf Finanzhilfen aus Steuermitteln herleiten und diese zu weiterer Agitation gegen die Allgemeingültigkeit der Menschen- und Bürgerrechte nutzen.

Die Gleichstellung der Geschlechter in der Landespolitik kam mit dieser Landtagswahl nicht voran. Der Frauenanteil an den Abgeordneten beträgt weniger als 30 Prozent, was vor allem auf die Männerparteien Piraten, FDP und CDU zurückzuführen ist. In der SPDFraktion stellen Frauen nur ein Drittel der Abgeordneten (2005: 41,9 Prozent). Allein bei den Grünen ist der weibliche Anteil an den Fraktionsmitgliedern größer als der männliche.

\subsection{Wählermobilisierung und Wählerwanderungen}

Insgesamt vermochten es die Parteien und ihre Kandidaten nicht, die Wahlberechtigten zu mobilisieren. Die Wahlbeteiligung war mit 59,6 Prozent gering. Außer 2000 (56,7 Prozent) und 2010 (59,3 Prozent) lag sie bei keiner Wahl seit 1947 so niedrig wie dieses Mal. Die Nichtwähler stellten den größten Anteil an den Wahlberechtigten. Zwar lockte die Piratenpartei durchaus beachtliche 70.000 von ihnen an die Urnen, die SPD sogar 120.000. Im Gegenverkehr wanderten aber 170.000 Wähler der CDU, der Linken und anderer Parteien ins Nichtwählerlager ab.

Nun sollten Nichtwähler nicht schlechthin als Verdrossene eingeschätzt werden. Dafür sind sie zu verschieden und Wahlabstinenz könnte im Gegenteil auch Ausdruck von Zufrie- 


\begin{tabular}{|l|c|c|c|c|c|c|c|c|}
\hline \multicolumn{2}{|l|}{ Tabelle 3: Wählerwanderungen 2012 gegenüber 2010 (in 1.000) } \\
\hline \multirow{3}{*}{ Die... } & \multicolumn{7}{|c|}{.. gewannen von/verloren an } \\
\cline { 2 - 8 } & $\begin{array}{c}\text { Nicht- } \\
\text { wähler }\end{array}$ & CDU & SPD & Grünen & FDP & Linke & Piraten & Sonstigen \\
\hline Nichtwähler & & 110 & -120 & -50 & -30 & 20 & -70 & 40 \\
CDU & -110 & & -190 & -20 & -160 & 0 & -60 & -20 \\
SPD & 120 & 190 & & 70 & 20 & 90 & -90 & -10 \\
Grünen & 50 & 20 & -70 & & -10 & 30 & -80 & -10 \\
FDP & 30 & 160 & -20 & 10 & & 10 & -40 & 0 \\
Linke & -20 & 0 & -90 & -30 & -10 & & -80 & -20 \\
Piraten & 70 & 60 & 90 & 80 & 40 & 80 & & 40 \\
Sonstigen & -40 & 20 & 10 & 10 & 0 & 20 & -40 & \\
\hline
\end{tabular}

Quelle: Infratest dimap, http://stat.tagesschau.de/flash/?wahl=2012-05-13-LT-DE-NW (Abruf am 20. Mai 2012).

denheit sein. Dennoch stellen sich bei einer Abstinenz von 40,4 Prozent Fragen ${ }^{80}$ : Bildet das Parlament unter diesen Umständen noch den Willen des Souveräns ab? Wurden die Lebenslagen und Belange jener, die der Wahl fernblieben, mangels kommunikativer Verknüpfung gar nicht mehr in die Kalküle der Parteien und ihrer Kandidaten einbezogen? Konnten sich zwei Fünftel der Wahlberechtigten in den personellen und programmatischen Angeboten der Parteien nicht wiederfinden? Oder werden Regionalparlamente nicht mehr ernst genommen?

Wären die Stimmberechtigten statt der Abstimmenden die Bezugsgröße, hätten die Piraten den Sprung über die Fünfprozenthürde nicht, die FDP ihn nur ganz knapp geschafft. Und würden Mandate im Maße der Wahlbeteiligung vergeben, wäre der Landtag von 181 auf 106 Sitze geschrumpft - was kurzfristig Einsparungen zur Folge hätte und mittelfristig die Parteien vielleicht zu mehr Engagement für die abseits stehenden Wahlberechtigten veranlassen würde.

Bezogen auf die Wählerwanderung war die Piratenpartei die große Gewinnerin. Zu ihr strömten Wähler aller Parteien: 90.000 von der SPD, je 80.000 von den Grünen und der Linken, 60.000 von der CDU sowie je 40.000 von der FDP und von anderen Parteien. Der Wahlsieg der SPD rührte nicht allein daher, dass es ihr gelungen war, Nichtwähler zu aktivieren. Vor allem gewann sie 190.000 Wähler der CDU und 70.000 von den Grünen. Von der Linken gingen 90.000 Stimmen zur SPD; gleich viele verließen sie in Richtung Piratenpartei. Die CDU verlor vor allem an die SPD. Dass sie 160.000 Stimmen an die FDP abgeben musste, war auch auf den Wunsch des bürgerlichen Lagers zurückzuführen, die FDP über die Fünfprozenthürde zu hieven und sie damit vor der Bedeutungslosigkeit zu bewahren.

Die Grünen gaben an zwei Mitbewerber ab: Auf der einen Seite wählten 70.000 ehemals grüne Wähler, die die Ministerpräsidentin behalten wollten, gleich die SPD statt einer Partei, die schwarz-grün nicht ausschloss. Auf der anderen Seite meinten 80.000, in den Piraten die Unbefangenheit, Ursprünglichkeit und Radikalität wiederzufinden, die beim Aufstieg der Grünen von der Graswurzel zu den Wipfeln des Regierens verloren gegangen waren.

80 Vgl. Dorothée de Nève, NichtwählerInnen - eine Gefahr für die Demokratie?, Opladen 2009, S. 205. 


\subsection{Wahlverhalten in unterschiedlichen sozialen Gruppen}

Während SPD und Grüne bei Frauen mehr Erfolg hatten als bei Männern, war es bei den Piraten anders herum. CDU und SPD blieben bei Jüngeren (18 bis 44 Jahre) beiderlei Geschlechts hinter ihren Gesamtergebnissen zurück, während die Grünen beziehungsweise die Piratenpartei bei ihnen überdurchschnittliche Ergebnisse erzielten. Nur noch knapp die Hälfte der nachwachsenden Generation der 18- bis 29-Jährigen wählte die „Volksparteien“. Bei den Frauen dieser Altersklasse überholten die Grünen die CDU und bei den Männern zog die Piratenpartei mit der CDU gleich. Die CDU schnitt am besten bei älteren Wählern ab. Die Zuwächse der FDP bei den Älteren sind wohl auf Verluste der CDU zurückzuführen.

Mit dieser Wahl wurde die SPD in Nordrhein-Westfalen wieder zur Partei der Arbeitnehmer und vor allem der Arbeiter. Mehr als die Hälfte der Gewerkschaftsmitglieder wählte Hannelore Kraft, während besser verdienende und vermögende Selbstständige traditionsgemäß CDU und FDP bevorzugten. Die Piratenpartei schnitt besonders gut bei Arbeitern ab. Auch Erwerbslose entschieden sich überdurchschnittlich häufig für die Piraten, daneben für die Linke und für sonstige Parteien.

\begin{tabular}{|c|c|c|c|c|c|c|c|c|}
\hline \multirow[t]{2}{*}{ Tabelle 4} & \multicolumn{8}{|c|}{$\begin{array}{l}\text { Wablverhalten nach Alter und Geschlecht bei der Landtagswahl in Nordrhein-Westfalen } \\
2012 \text { (in Prozent, in Klammern Differenz zu 2010) }\end{array}$} \\
\hline & $\mathrm{CDU}$ & SPD & Grüne & FDP & Linke & Piraten & Sonstige & $\begin{array}{l}\text { Differenz } \\
\text { zu } 2010^{*}\end{array}$ \\
\hline \multicolumn{9}{|c|}{ Insgesamt } \\
\hline Alle & $26(-8)$ & $39(+5)$ & $11(-1)$ & $9(+2)$ & $3(-3)$ & 8 & 4 & $(+6)$ \\
\hline $18-29$ & $19(-5)$ & $30(+1)$ & $16(-1)$ & $7( \pm 0)$ & $3(-3)$ & 16 & 10 & $(+9)$ \\
\hline $30-44$ & $24(-7)$ & $34(+5)$ & $14(-3)$ & $9(+1)$ & $3(-3)$ & 10 & 6 & $(+6)$ \\
\hline $45-59$ & $23(-6)$ & $43(+7)$ & $14(-1)$ & $7( \pm 0)$ & $3(-5)$ & 8 & 3 & $(+5)$ \\
\hline $60+$ & $34(-10)$ & $45(+6)$ & $6( \pm 0)$ & $10(+5)$ & & 3 & & $( \pm 0)$ \\
\hline \multicolumn{9}{|l|}{ Frauen } \\
\hline Alle & $26(-10)$ & $41(+6)$ & $13(-1)$ & $8(+2)$ & & 6 & 4 & $(+5)$ \\
\hline $18-29$ & $18(-4)$ & $33(+1)$ & $19(-2)$ & $7( \pm 0)$ & $3(-2)$ & 11 & 9 & $(+7)$ \\
\hline $30-44$ & $24(-6)$ & $37(+7)$ & $17(-2)$ & $8(+1)$ & & 7 & 5 & $(+4)$ \\
\hline $45-59$ & $22(-9)$ & $44(+8)$ & $14(-2)$ & $7( \pm 0)$ & $3(-2)$ & 6 & 3 & $(+4)$ \\
\hline $60+$ & $35(-12)$ & $44(+6)$ & $7( \pm 0)$ & $9(+4)$ & & & & \\
\hline \multicolumn{9}{|l|}{ Männer } \\
\hline Alle & $26(-8)$ & $37(+4)$ & $10(-1)$ & $9(+2)$ & $3(-4)$ & 10 & 5 & $(+7)$ \\
\hline $18-29$ & $20(-6)$ & $28(+1)$ & $13( \pm 0)$ & $7( \pm 0)$ & $3(-4)$ & 20 & 10 & $(+10)$ \\
\hline $30-44$ & $24(-7)$ & $30(+3)$ & $12(-3)$ & $11(+2)$ & $4(-3)$ & 13 & 7 & $(+9)$ \\
\hline $45-59$ & $23(-6)$ & $41(+6)$ & $13( \pm 0)$ & $7( \pm 0)$ & $3(-7)$ & 9 & 4 & $(+7)$ \\
\hline $60+$ & $33(-10)$ & $45(+7)$ & $4(-2)$ & $11(+5)$ & & 4 & & $(+2)$ \\
\hline \multicolumn{9}{|c|}{$\begin{array}{l}\text { * Differenz zu 2010: „Piraten“ und „andere“ zusammen. } \\
\text { Quelle: Forschungsgruppe Wahlen, Wahl in Nordrhein-Westfalen, a.a.O. (Fn. 39), S. } 38 \text { f., S. 41; Ursula } \\
\text { Feist / Hans-Jürgen Hoffmann, Die nordrhein-westfälische Landtagswahl vom 9. Mai 2010: Vom Abwar- } \\
\text { ten zur Kehrtwende, in: ZParl, 41. Jg. (2010), H. 4, S. } 766 \text { - 787, S. 782; eigene Berechnungen. }\end{array}$} \\
\hline
\end{tabular}




\begin{tabular}{|l|c|c|c|c|c|c|c|}
\hline Tabelle 5: Wablentscheidung bei der Landtagswahl in Nordrhein-Westfalen 2012 nach Berufs- \\
gruppen, Erwerbsstatus, Gewerkschaftszugehörigkeit und Konfession (in Prozent)
\end{tabular}

Ihr sehr gutes Ergebnis bei katholischen Wählern zeigt, dass die CDU noch immer die Partei des Katholizismus in Nordrhein-Westfalen ist. Hingegen sammelten sich die Protestanten überwiegend bei der SPD. Andersgläubige und Religionsfreie verwiesen die CDU sogar auf den vierten Platz und entschieden sich vor allem für SPD, Grüne, Piratenpartei und Linke.

Die SPD gewann in den Großstädten 43,1 Prozent der Zweitstimmen, während die CDU auf nur 24,7 Prozent kam. In Großstädten mit mehr als 500.000 Einwohnern erhielt die CDU lediglich 20,5 Prozent; hingegen übertrafen die Grünen mit 15,4 (-0,7) und die FDP mit 9,2 Prozent $(+2,6)$ hier ihre landesweiten Ergebnisse deutlich. In Gemeinden unterhalb von 100.000 Einwohnern schnitt die CDU mit 30,2 Prozent überdurchschnittlich ab, verlor aber auch hier den ersten Platz an die SPD. ${ }^{81}$

\subsection{Bundespolitische Auswirkungen}

Für den Bundesrat hatte das Wahlergebnis keine Veränderung des parteipolitischen Kräfteverhältnisses zur Folge. Es bestätigte aber den Verlust der hegemonialen Stellung der Union und eine Linksverschiebung der Politik: CDU und FDP verfügen nur noch in fünf Ländern über Regierungskoalitionen und die Umfragewerte für die Bundesebene deuten seit Anfang 2010 auf den Verlust der parlamentarischen Mehrheit hin, wenn am nächsten Sonntag gewählt würde. ${ }^{82}$ Vor allem für die CDU stellt sich nicht erst seit dieser Landtagswahl die Frage nach Alternativen zur FDP, wenn sie nicht auf Dauer auf Große Koalitionen angewiesen sein will.

Die Unionsparteien ließen Norbert Röttgen tief stürzen. Unmittelbar nach der Wahl bezeichnete der CSU-Vorsitzende Horst Seehofer deren Ausgang als „Desaster mit Ansage“.

81 Vgl. Forschungsgruppe Wahlen, Wahl in Nordrhein-Westfalen, a.a.O. (Fn. 39), S. 73.

82 Vgl. http://www.wahlrecht.de/umfragen/index.htm, a.a.O. (Fn. 10). 
Röttgen habe den Sieg verspielt. Dies schwäche ihn als Bundesminister. ${ }^{83}$ Zwar sah die Kanzlerin am Montag nach der Wahl keinen Anlass für eine Kabinettsumbildung ${ }^{84}$, doch erwies sie sich wieder einmal als Meisterin der abrupten Kehrtwende: Am Mittwoch entzog sie Röttgen das Bundesumweltministerium. ${ }^{85}$ Empörung über Merkels Entschluss, wie sie hier und da laut wurde, war allerdings unangebracht: Da Röttgen selbst darauf bestanden hatte, dass die Partei entscheide, wo sein Platz im Fall einer Niederlage sei ${ }^{86}$, war es nur konsequent, dass die CDU-Vorsitzende ihn auf den Status eines Abgeordneten im Deutschen Bundestag verwies. Damit widerlegte sie zugleich ihre Behauptung, die Landtagswahl habe keine Auswirkungen auf die Bundesebene.

Der Erfolg der SPD mehrte Hannelore Krafts Einfluss im Bund. Vier Wochen nach der Landtagswahl verdrängte sie die Kanzlerin vorübergehend von Platz eins in der Rangliste der beliebtesten deutschen Politiker. ${ }^{87}$ Zwar will Kraft im Unterschied zu Frank-Walter Steinmeier, der der SPD mit 23 Prozent das kläglichste Bundestagswahlergebnis seit 1949 bescherte, und zu den gescheiterten Ministerpräsidenten Sigmar Gabriel und Peer Steinbrück nicht ins Kanzleramt einziehen. Ohne oder gar gegen Kraft und ihren mitgliederstarken Landesverband dürfte aber wohl keiner von ihnen und auch niemand anderer eine Chance haben, die SPD in den nächsten Bundestagswahlkampf zu führen.

Christian Lindner, dessen Wahlkampfstrategie die FDP im Landtag hielt, galt spätestens von da an als kommende Führungspersönlichkeit auch auf Bundesebene. Seinen eigenen Worten zufolge strebt er den Bundesvorsitz nicht an ${ }^{88}$ - doch er könnte ihn haben, wenn er wollte. Ob aber die FDP in den nächsten Bundestag zurückkehren kann, bleibt trotz ihres Erfolgs in Nordrhein-Westfalen ungewiss. Ende Mai 2012 kam sie bei der Sonntagsfrage nur auf vier bis fünf Prozent. ${ }^{89}$

Für die Linke, die sich 2010 von ihrem Einzug in den nordrhein-westfälischen Landtag eine Verankerung auch in den alten Bundesländern erhofft hatte, war das Wahlergebnis ernüchternd. Es wäre indes verfrüht, einen generellen Niedergang der Linken in Westdeutschland zu prognostizieren. Vorerst bleibt sie in fünf von zehn Landesparlamenten vertreten.

\section{Regierungsbildung und Formierung der Opposition}

Die Grünen konnten dank des guten Wahlergebnisses der SPD in der Regierung verbleiben. Der 189-seitige Koalitionsvertrag wurde am 18. Juni unterzeichnet, nachdem Parteitage von

83 Vgl. „Seehofer: Das können Sie alles senden!“, in: heute journal plus vom 14. Mai 2012, http:// www.zdf.de/ZDFmediathek/beitrag/video/1641980/Seehofer-Das-koennen-Sie-alles-senden\%2521\#/beitrag/video/1641980/Seehofer-Das-koennen-Sie-alles-senden! (Abruf am 11. Juni 2012); Handelsblatt vom 14. Mai 2012, www.handelsblatt.com/politik/deutschlnd/nrwwahl-2012/nach-wahl-debakel-roettgen-soll-die-zeche-zahlen/6628572.html (Abruf am 16. Mai 2012).

84 Vgl. „Merkel gratuliert Kraft - und hält zu Röttgen“, in: Tagesschau vom 14. Mai 2012, http:// www.tagesschau.de/inland/nrwwahl272.html (Abruf am 11. Juni 2012).

85 Vgl. „Kanzlerin Merkel entlässt Umweltminister Röttgen“, in: Tagesschau vom 16. Mai 2012, http://www.tagesschau.de/multimedia/video/video1116194.html (Abruf am 18. Mai 2012).

86 Vgl. SZ online vom 15. März 2012, a.a.O. (Fn. 50).

87 Vgl. „Kraft beliebter als Merkel“, in: Rheinische Post vom 16. Juni 2012, S. 4.

88 Vgl. „Eine Zukunft namens Lindner“, in: SZ vom 15. Mai 2012, S. 2.

89 Vgl. http://www.wahlrecht.de/umfragen/index.htm, a.a.O. (Fn. 10). 


\begin{tabular}{|l|l|}
\hline Tabelle 6: Die Landesregierung Nordrhein-Westfalen (Stand: 21. Juni 2012) \\
\hline Ministerpräsidentin & Hannelore Kraft (SPD) \\
\hline $\begin{array}{l}\text { Stellvertretende Ministerpräsidentin und Ministeri- } \\
\text { um für Schule und Weiterbildung }\end{array}$ & Sylvia Löhrmann (Bündnis 90/Die Grünen) \\
\hline Ministerium für Inneres und Kommunales & Ralf Jäger (SPD) \\
\hline Justizministerium & Thomas Kutschaty (SPD) \\
\hline $\begin{array}{l}\text { Ministerium für Innovation, Wissenschaft und For- } \\
\text { schung }\end{array}$ & Svenja Schulze (SPD) \\
\hline Ministerium für Familie, Kinder, Jugend und Sport & Ute Schäfer (SPD) \\
\hline $\begin{array}{l}\text { Ministerium für Klimaschutz, Umwelt, Landwirt- } \\
\text { schaft, Natur- und Verbraucherschutz }\end{array}$ & Johannes Remmel (Bündnis 90/Die Grünen) \\
\hline Ministerium für Arbeit, Integration und Soziales & Guntram Schneider (SPD) \\
\hline Finanzministerium & Norbert Walter-Borjans (SPD) \\
\hline $\begin{array}{l}\text { Ministerium für Wirtschaft, Energie, Industrie, Mit- } \\
\text { telstand und Handwerk }\end{array}$ & Garrelt Duin (SPD) \\
\hline $\begin{array}{l}\text { Ministerium für Bauen, Wohnen, Stadtentwicklung } \\
\text { und Verkehr }\end{array}$ & Michael Groschek (SPD) \\
\hline $\begin{array}{l}\text { Ministerium für Gesundheit, Emanzipation, Pflege } \\
\text { und Alter }\end{array}$ & Barbara Steffens (Bündnis 90/Die Grünen) \\
\hline $\begin{array}{l}\text { Ministerium für Bundesangelegenheiten, Europa } \\
\text { und Medien }\end{array}$ & Angelica Schwall-Düren (SPD) \\
\hline Quelle: Eigene Zusammenstellung. & \\
\hline
\end{tabular}

SPD (Hagen) und Grünen (Duisburg) ihm zwei Tage zuvor zugestimmt hatten. Er handelt in epischer Breite und mit vielen Leerformeln entlang den Zuständigkeiten der Ministerien und ihrer Abteilungen den nicht durchweg lesenswerten Aufgabenbestand und Wunschkatalog einer Landesregierung ab. Nur selten wird es konkret.

Die Landesregierung wolle die „Kultur des Dialogs [...] fortsetzen“, heißt es am Beginn und sie bekennt sich zum Ziel der Vollbeschäftigung, ohne darzulegen, wie sie ihm näherkommen will. An den Schulen sollen Ressourcen, die infolge sinkender Schülerzahlen frei werden, für kleinere Lerngruppen und die Inklusion genutzt werden. Durch Bildungsinvestitionen sollen „Gebühren, Mangel an U3-Plätzen und Hemmnisse für Kinder mit Behinderung [...] abgebaut werden“. An den Kosten hierfür soll sich der Bund beteiligen. Kindertageseinrichtungen sollen „schrittweise“ beitragsfrei werden. Der Nichtraucherschutz soll verbessert, eine „individualisierte anonymisierte Kennzeichnung der Polizei“ eingeführt, der Ladenschluss an Sonnabenden auf 22 Uhr vorverlegt und das Mindestalter für die Teilnahme an Landtagswahlen auf 16 Jahre gesenkt werden..$^{90}$

Eine Wende zu Lasten des motorisierten Individualverkehrs enthält der Koalitionsvertrag nicht. Stattdessen sollen Autobahnen verbreitert, Straßenbaumittel des Bundes auf jeden Fall abgerufen und neue Landesstraßen gebaut werden. Mit anderenfalls möglichen Einsparungen hält sich der Koalitionsvertrag nicht auf. Für den Luftverkehr, dessen ungehemmten

90 Vgl. NRWSPD, Bündnis 90/Die Grünen NRW, Koalitionsvertrag 2012-2017. Verantwortung für ein starkes NRW - Miteinander die Zukunft gestalten, S. 2, S. 6, 13 f., S. 17, S. 19 f., S. 44, S. 131, S. 147, S. 151. 
Vormarsch die Münchener am Tag nach Verabschiedung des Koalitionsvertrages mit einem Bürgerentscheid stoppten, wird ein Luftverkehrskonzept in Aussicht gestellt, das Unvereinbares vereinbar machen soll.

Die Verantwortlichkeiten für die Energiepolitik werden komplizierter. Die Ministerpräsidentin will sich dieses Themas mit einer eigenen Abteilung in der Staatskanzlei annehmen. Daneben bleibt ein Fachministerium für Energie bestehen, in dessen Zuständigkeit aber nicht die erneuerbaren Energien fallen. Sie ressortieren weiterhin im Umweltministerium. Energieintensive Unternehmen sollen langfristig „vollständig [...] mit Erneuerbaren Energien versorgt" werden. Parallel dazu brauche es fossile Kraftwerke, aber - da ja bereits die erste rot-grüne Koalition die Ausweitung des Abbaugebiets genehmigt hatte ${ }^{11}$ - keine neuen Braunkohlentagebaue.

Ohne die Erfahrungen der Kommunalaufsichten mit den selbstgemachten Haushaltsproblemen der Gemeinden auszuwerten, bescheinigt der Koalitionsvertrag den Kommunen, „strukturell unterfinanziert“ zu sein. Er lehnt ein „Kaputtsparen“ ab, ohne nach vorherigem „Kaputtverausgaben“ zu fragen, und will die „finanzielle Handlungsfähigkeit“ der Kommunen mit Bundesmitteln „stärken“.

Auf Landesebene seien „Haushaltskonsolidierung und vorsorgende Politik“, also gleichzeitig weniger und mehr ausgeben, „zwei Seiten ein und derselben Medaille“. Einsparungen sollen durch Aufgabenkritik und Effizienzsteigerungen sowie durch die Umstellung von Förderprogrammen auf Darlehen erreicht werden. Von einer Übereinkunft mit den Unternehmen über eine Ausbildungsplatzgarantie erwartet die Koalition die Einsparung von 500 Lehrern in Berufskollegs. Eine Kiesabgabe und Bundesratsinitiativen für Steuererhöhungen sollen die Haushaltspolitik einnahmeseitig unterstützen. ${ }^{92}$

Der Landtag wählte am 31. Mai 2012 die Sozialdemokratin Carina Gödecke aus Bo-chum zu seiner Präsidentin. Dem Präsidium gehören des Weiteren an: der bisherige Landtagspräsident Eckhard Uhlenberg (CDU) aus Werl als erster, Oliver Keymis (Grüne) aus Meerbusch wie bisher als zweiter, der bisherige Fraktionsvorsitzende Gerhard Papke (FDP) aus Königswinter als dritter und Daniel Düngel (Piratenpartei) aus Oberhausen als vierter Vizepräsident.

Als Vorsitzende ihrer Landtagsfraktionen bestätigten die SPD Norbert Römer aus Soest, die CDU Karl-Josef Laumann aus Hörstel und die Grünen Reiner Priggen aus Aachen. Die FDP ersetzte Gerhard Papke durch Christian Lindner aus Wermelskirchen. Die Piratenpartei wählte Joachim Paul aus Neuss zu ihrem Vorsitzenden.

Der Landtag wählte Hannelore Kraft am 20. Juni 2012 mit 137 Stimmen (94 Nein, drei Enthaltungen) zur Ministerpräsidentin. Aufgrund des veränderten Kräfteverhältnisses stellt die SPD im Kabinett Kraft II neun Minister statt bisher acht, die Zahl der grünen blieb mit drei gleich. Inklusive Ministerpräsidentin setzt sich das Kabinett aus sechs Frauen und sieben Männern zusammen.

91 Vgl. Stefan Bajohr, Fünf Jahre und zwei Koalitionsverträge. Die Wandlung der Grünen in Nordrhein-Westfalen, in: ZParl, 32. Jg. (2001), H. 1, S. 146 - 170, vor allem S. 162 ff.

92 Vgl. Koalitionsvertrag, a.a.O. (Fn. 91), S. 4 f., S. 12, S. 23, S. 46 f., S. 55 f., S. 59, S. 101 f., S. 141 f., S. 180, S. 182. 


\section{Zusammenfassung}

(1) Die rot-grüne Minderheitsregierung in Nordrhein-Westfalen hatte entgegen den Erwartungen und dank des Zustandekommens unterschiedlicher Mehrheiten Weichenstellungen vorgenommen. In der Auseinandersetzung über den Haushaltsentwurf 2012 legten sich CDU, FDP und Linke auf ein Nein in der zweiten Lesung fest. Die Ministerpräsidentin erklärte die Verabschiedung des Landeshaushalts zur Geschäftsgrundlage ihrer Regierung und bat deshalb die Fraktionen von SPD und Grünen, die Auflösung des Landtags zu beantragen.

(2) FDP und Linke hatten darauf gesetzt, dass ihr Nein zur zweiten Lesung „unschädlich“ wäre. Nachdem ein Rechtsgutachten anders ausgefallen war, konnten sie sich dem Antrag von Rot-Grün nicht verweigern. Der Landtag wurde einstimmig aufgelöst.

(3) Zur Zeit der Selbstaufösung signalisierten die Umfragen einen deutlichen Vorsprung für Rot-Grün. Die CDU besaß nur geringe Chancen für eine Mehrheit. Der FDP und der Linken drohte das Ausscheiden aus dem Landtag, während die Piratenpartei mit ihrem Einzug rechnen konnte.

(4) Der Wahlkampf wurde von Personen bestimmt. Zugpferd der Sozialdemokratie war Ministerpräsidentin Hannelore Kraft, die die SPD wieder als Partei der „kleinen Leute“ und der sozialen Gerechtigkeit ins Rennen schickte. Ihrem Gegenkandidaten, Bundesminister Norbert Röttgen (CDU), gelang es nicht, die Wahlberechtigten anzusprechen. Die FDP schwamm mit Christian Lindner auf einer Welle der Mediengunst in den Landtag.

(5) Allein Piratenpartei und Linke hatten Wahlprogramme ausgearbeitet. Die anderen Parteien begnügten sich mit Wahlaufrufen, Kurzfassungen oder Aktualisierungen.

(6) Über zwei Fünftel der Wahlberechtigten nahmen nicht an dieser Landtagswahl teil deutlich mehr als für CDU und FDP stimmten. Dies weist auf Legitimationsprobleme des regionalen Parlamentarismus hin.

(7) Gewinner der Wahl waren die SPD, die sich wieder auf Werte einer Volkspartei zubewegte, die FDP und die Piratenpartei. Sie zog erwartungsgemäß erstmals in den Landtag ein. Wahlverlierer waren die CDU, die so schlecht abschnitt wie nie zuvor, und die Linke, die an der Fünfprozenthürde scheiterte.

(8) Aus dem Nichtwählerreservoir und von allen Parteien außer den Piraten wanderten Stimmen zur SPD. Die Piratenpartei sammelte bei den Nichtwählern und bei sämtlichen anderen Parteien Stimmen ein. Außer an die Linke verlor die CDU Stimmen an alle anderen Parteien und ans Lager der Nichtwähler. Grüne und Piratenpartei waren bei jüngeren Wählern überdurchschnittlich erfolgreich.

(9) Die SPD wurde wieder zur Arbeitnehmer- und Großstadtpartei. Bei katholischen Wählern schnitt sie unterdurchschnittlich, bei protestantischen überdurchschnittlich ab.

(10) Frauen stellen nicht einmal dreißig Prozent der Landtagsabgeordneten. Als Männerdomänen präsentieren sich die FDP- und die Piraten-Fraktion. Die Grünen zählen mehr weibliche als männliche Abgeordnete.

(11) Das Wahlergebnis stärkte die SPD-Spitzenkandidatin Kraft auf Bundesebene und führte zum Absturz des CDU-Spitzenkandidaten Röttgen. Die CDU verlor ihre hegemoniale Stellung im Bund. Die Linke muss um ihre Präsenz in den westdeutschen Landtagen kämpfen. Der Verbleib der FDP im Bundestag bleibt fraglich.

(12) Die Wahl verwandelte die Minderheits- in eine Mehrheitsregierung. Das Regierungsprogramm ist als Fortsetzung der 2010 begonnenen Politik konzipiert. 